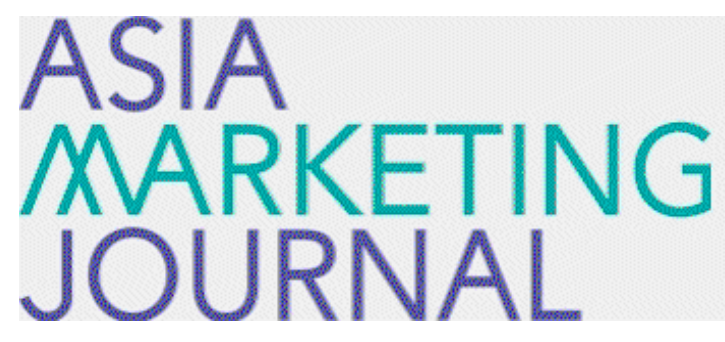

ASIA MARKETING JOURNAL

Volume 19 | Issue 2

Article 2

7-30-2017

\title{
Is a Cause-Related Self-Prevention Campaign a Good CSR Strategy?
}

Jihye Park

Follow this and additional works at: https://amj.kma.re.kr/journal

Part of the Marketing Commons

\section{Recommended Citation}

Park, Jihye (2017) "Is a Cause-Related Self-Prevention Campaign a Good CSR Strategy?," Asia Marketing Journal: Vol. 19 : Iss. 2 , Article 2.

Available at: https://doi.org/10.15830/amj.2017.19.2.25

This Article is brought to you for free and open access by Asia Marketing Journal. It has been accepted for inclusion in Asia Marketing Journal by an authorized editor of Asia Marketing Journal. 


\section{Is a Cause-Related Self-Prevention Campaign a Good CSR Strategy?: Effects of Negative Social Acceptance and Consumer Attitude on Biased Evaluations*}

This paper addresses the central issue of whether it is effective for a firm to discourage the purchase of its own product in order to support a social cause. The objectives of this study were: a) to examine whether a cause-related self-prevention ad would stimulate more positive evaluations compared to promotional ad, particularly when the product category is more negatively socially accepted; and 2) to determine if a negative attitude toward the product could induce a boomerang effect of a selfprevention ad. Results from three experiments revealed that socially responsible prevention campaigns against firm's own product may be more effective for the product category negatively associated with social concerns or welfare. If products are more limited in the social context, communications of product prevention are beneficial to improve the public image of the brand. However, the self-hurting approach may be inappropriate for potential customers who currently possess a strong negative attitude toward the product.

Key words: Cause-related marketing, self-prevention, social acceptance, attitude

\section{Introduction}

Nestlé's breastfeeding campaign informs people that mother's milk is the best source of nutrition for babies. Heineken, along with other alcohol manufacturers, have ad campaigns exhorting consumers to drink responsibly. Shell recently began a fuel-saving campaign claiming: "Learn to drive more efficiently and save on fuel." These types of cause-related marketing campaigns are somewhat unusual because of their purported claims in discouraging the use of the advertiser's product or apparently arguing

* This work was supported by Hankuk University of Foreign Studies Research Fund of 2017

** PhD, Professor of marketing College of Business Hankuk University of Foreign Studies (jihyepark@hufs.ac.kr),

Corresponding Author 
its product or its quiddity. These "ironic" approaches are often observed in some industries that are held to socially blameworthy (e.g., "sin" businesses), in which their products cause public health threats or devastate natural environments. Cause-related self-prevention campaigns portray the firm as truthful and honest by seemingly denigrating its own product or brand. This strategy is a kind of ruse in which a firm seeks to improve its public image and thereby convert non-purchasers to purchasers (Simmons \& Becker-Olsen 2006). However, cause-related self-prevention campaigns are risky for firms because prevention messages can discourage the purchase of a product, thereby negatively influencing the firm's financial gains (Laugesen \& Meads 1991). In brief, these kinds of corporate socially responsible campaigns raise the issue of whether a somewhat risky strategy is being "too clever by half," that is, counterproductive when it comes to the Bottom Line, which is their overriding goal, for they are not eleemosynary organizations per se.

The effectiveness of the self-prevention campaign can be increased by the extent to which the product is negatively perceived by the public or strategically situated in a debate about social well-being. As a product of the advertiser seemingly supports the public interest, the cause-related self-prevention campaign can be more viewed as ostensibly honest acts by an advertiser, and thus will be evaluated positively by the average or naïve consumers.
But some consumers, who already formed negative attitudes toward the product, may react negatively to the cause-related selfprevention efforts in order to be consistent with their pre-existing attitudes. The ultimate goal of cause-related marketing activities targeting the public is to gain or strengthen positive brand image, hence it is necessary to examine how the cause-related self-prevention advertising is interpreted by those consumers who already have negative attitudes toward the product. Thus, the objectives of this study were first to examine whether a cause-related self-prevention advertisement would stimulate more positive evaluations, as compared with a promotional $\mathrm{ad}$, particularly if the product category is more negatively socially accepted (Study 1) and next, to determine if negative attitudes toward the product could induce a boomerang effect for a cause-related self-prevention ad (Study 2). This research provides meaningful implications for the firms whose major marketing concern about selling the products that have some conflicts with social welfare (e.g., cigarettes, fast food, alcohol). Results are helpful for them to choose a right cause, product, and target consumer for planning effective cause-related campaigns. 


\section{Study 1. Effect of product category negativity on evaluations of self-prevention ads}

\subsection{Theoretical background}

A self-prevention ad that discourages product purchase can be perceived as unusual, uncommon, and salient, as compared with a promotional ad that solicits the purchasing of a product. Consumers are likely to view a purportedly philanthropic campaign as atypical or surprising, if it is more "independent" concerning the direct purchasing of the sponsor's product (Menon \& Kahn 2003). For the product category (e.g., tobacco, alcohol, or fast food) that conflicts to a greater extent with social welfare (Kim and Shanahan 2003; Moore 2005), consumers tend to perceive self-prevention campaigns as part of an advertiser's greater trade-offs. For example, McDonald's ad in France-with a claim of "no reason to eat excessive amounts of fast food, nor go more than once a week to McDonald's" - allows consumers to presume there are corresponding trade-offs, by which supporting a social cause decreases their product value. In contrast with the aforementioned converse situation, if the product in the ad does not deviate much from social welfare (e.g., "save paper, save trees, save the world" claimed by Kleenex), consumers may not feel greater trade-offs. Hence, the self-prevention ad supporting the advertiser's voluntary admission of product negativity can be perceived as even more salient. Thus, the novelty or unusual aspects of that inconsistent structure in the self-prevention ad captures more attention (Arias-Bolzmann et al. 2000), making it more likely to be processed, considered diagnostic, and later easily recalled, than a typical promotional ad that is the norm or expected to appear in a given context (Lynch \& Srull 1982; O’Brien $\&$ Wolford 1982). Because of the perceived salience and novelty of a self-harming message, consumers are more persuaded to pay attention and process the ad as the significance of product negativity increases (Crowely \& Hoyer 1994). Thus, it is expected that as the product is less socially accepted, individuals are induced to pay more attention to an ad that discourages product purchase in order to ostensibly support a social cause. On the other hand, if the product is more socially accepted, then the degree of incongruence decreases, thereby lowering the perception of salience. Therefore, based on the literature, the following hypothesis was developed.

$H_{1}$ : If the product (category) is less socially accepted, a self-prevention ad is more recalled than a promotional ad. However, if the product (category) is more socially accepted, there is no difference of ad recall between a self-prevention ad and a promotional ad. 
Advertisers who acknowledge counterarguments or deliberately point out the weaknesses of their products are likely to be perceived as somehow acting against their own interest. The inclusion of negative product information in an ad is not a normative influence per se in advertising because it can actually reduce product sales. Consumers tend to interpret the ad by asking "why" to an advertiser's action and then assign causes. They believe that an honest advertiser communicates true information in order to help consumers make the right decision on a product (Settle \& Golden 1974). Thus, the ad is more likely to be perceived as valid, rather than as biased toward the advertiser's own self-interest. Consequently, the firm proffering negative product attribute information with consumers is likely to be viewed as more believable or honest, compared with the firm presenting information only about positive attributes (e.g., Golden \& Alpert 1987; Jones \& Davis 1965; Kamins \& Assael 1987; Settle \& Golden 1974; Smith \& Hunt 1978; Swinyard 1981).

Similarly, several studies (e.g., Priester \& Petty 1995) reported that if the sponsor brand focused on a social cause that was independent from the purchasing of a sponsor brand's product or appeared to lack a vested self-interest, then the credibility of a sponsor was enhanced, so leading to consumers having greater trust in the ad. If consumers believe that the purpose of cause-related activity is to increase sales, then they tend to react cynically to the campaign. For example, a study showed that a grocery store that collected donations of a product sold in the store was viewed as reflecting more of the store's self-interest in selling products than a philanthropic interest, and thereby resulted in negative evaluations of the sponsor brand (Drumwright 1996; Ellen et al. 2000). Thus, it is expected that the selfprevention ad is more effective in generating credibility for an advertiser and trust in an ad, compared with a typical promotional ad, when the product is less likely to be socially accepted. Therefore, based on the literature review, the following hypothesis was developed:

$\mathrm{H}_{2}$ : If the product (category) is less socially accepted, a self-prevention ad is perceived to be more trustworthy than a promotional ad. However, if the product (category) is more socially accepted, there is no difference of ad trust between a selfprevention ad and a promotional ad.

A self-prevention approach seemingly disclosing negative aspects of its own product (e.g., "Alcohol can produce impairments to brain such as slowed reaction times") to support a related cause (e.g., "Don't drink and drive"), thereby bolstering the advertiser's credibility and resulting in positive brand evaluations. An important upshot is that consumers tend to make favorable judgments about a featured 
brand that does not explicitly reveal an obvious interest in sales and allegedly makes some "sacrifice" to supposedly support a social cause. Thus, all these kinds of complex tactical maneuvers can result in greater trust and persuasion for the ad, thus realizing an important goal of a more positive brand attitude (Etgar \& Goodwin 1982). Menon and Kahn (2003) found that the strategy of supporting a cause that was thought by consumers to be independent of product sales was more appropriate for stimulating favorable evaluations for the sponsor brand, compared with support that was aimed at encouraging the purchase of the brand. Furthermore, this tendency strengthens as the public more negatively evaluates a product. Thus, if the product is more undesirable and less accepted by society, then the self-prevention approach can result in actually impeding a firm's sales. It is expected that if the product is more likely to go against the public interest or social welfare, then consumers tend to evaluate the brand in a self-prevention ad more positively than the brand in a promotional ad. However, if the product is less relevant to negative social consequences, consumers are less likely to view a self-prevention ad as an act against the firm's interest, as compared with the promotional ad. Therefore, the following hypothesis was developed:

$H_{3}$ : If the product (category) is less socially accepted, the brand in a self-prevention ad is more positively evaluated than the brand in a promotional ad. However, if the product (category) is more socially accepted, there is no difference of brand evaluations between a self-prevention ad and a promotional ad.

The first experiment examined the effect of social acceptance of a product on evaluations of a cause-related self-prevention ad. The interpretation of a self-prevention ad depends on how negatively a product category is evaluated. When a product category is less socially accepted, support for a social cause that is contradictory to the nature of the product implies a greater sacrifice in product sales. People tend to positively process and evaluate a cause-related self-prevention ad when social acceptance of a product is more negative.

\subsection{Experiment}

\subsubsection{Experimental Manipulation and Procedure}

The first experiment employed a 2 X 2 between subjects' factorial design: Product social acceptance (less accepted vs. more accepted) by ad type (self-prevention ad vs. promotional ad). First, in order to develop appropriate experiment stimuli, a pretest was conducted. Twenty undergraduate students (average age of 21 years old, 50\% males) who 
were recruited on campus rated product negativity for five product categories (burger, instant noodle, tobacco, beer, and pizza). Following Kim and Shanahan (2003) and Moore (2005), social acceptance of a product is defined as the amount of conflict to a greater extent with social welfare. To select the product categories that are more or less socially accepted, five items from a social acceptance scale developed by Taylor and Todd (1995) was used. All items used a 7-point Likert-type scale ranging from 1 ("Strongly disagree" or "Unlikely") to 7 ("Strongly agree" or "Likely"). Based on the pretest, among the five product categories, burger was ranked as the least negative $\left(M_{\text {Burger }}=3.78\right)$, whereas tobacco $\left(M_{\text {Tobacco }}=\right.$ 2.03) was ranked as the most negative in social acceptance. Thus, burger and tobacco were selected for further stimuli development.

Four mock target advertisements were created to closely mimic the design of the recent cause-related self-prevention advertisement. A well-known local brand was chosen for each product category to increase the reality of the ad in the advertisement. The cause-related self-prevention advertisement that discourages product purchase included a main message to reduce smoking or eating burgers. The prevention message was carefully developed so that it would not target personal behavior or alleviate negative emotional states for those who were involved in the relevant behavior in the ad. The promotional advertisement that solicits product purchase communicated a positive brand concept. The amount of image and text information used in the ad was controlled across treatment conditions.

Participants were randomly assigned to treatment groups. They were asked to read the general instructions regarding the experiment and guided to view a small booklet containing three one-page color-printed advertisements, including two filler ads and one target ad positioning in the middle of a booklet. After viewing the three advertisements, participants were asked to return the ad booklet and respond to a questionnaire. Participants were first asked to recall what they saw in the ad and responded to six items in a brand attitude scale developed by Stayman and Batra (1991). Four items of ad trust developed by Putrevu and Lord (1994) were also assessed. All items used a 7-point Likert-type scale ranging from 1 ("Strongly disagree" or "Very unlikely") to 7 ("Strongly agree" or "Very likely").

\subsection{Results}

A total of 121 undergraduate students (mean age 23 years old, $45 \%$ males, $20 \%$ in business major) volunteered to participate in this study. Extra course credit and candy bars were provided as incentives. Among those $(n=61)$ who were exposed to the tobacco ads, about 31 percent $(n=19)$ smoked daily. Their smoking tendency was slightly higher than the smoking 
rate $(22.9 \%)$ of adult population in Korea or the average smoking rate $(21.13 \%)$ in OECD countries (OECD 2013). Approximately 88 percent of the participants who were exposed to the burger ads $(n=59)$ visited a restaurant for a burger at least once a week $(n=52)$. Manipulation checks provided evidence of successful manipulations of product social acceptance. Results of univariate analyses of variance revealed a difference in perceived product social acceptance between tobacco and burger $[F(1,119)=56.24, p<.001]$. Tobacco $\left(M_{t}=2.10, S D_{t}=1.00\right)$ was perceived as less socially accepted than the burger $\left(M_{b}=3.36, S D_{b}=.84\right)$.

Results of a univariate analysis of variance revealed a significant interaction effect of product social acceptance and ad type on ad recall $[F(1,117)=4.34, p<.05]$. Post-hoc analyses of one-way ANOVA revealed that for a socially less accepted product, people who were exposed to a self-prevention ad ( $M_{\text {less-prev }}$ $=5.71$ ) recalled the information on the ad more than those who were exposed to a promotional ad $\left(M_{\text {less-pro }}=4.71\right)[F(1,60)=$ 4.82, $p<.05]$. However, for a socially more accepted product, no difference of ad recall was found between a self-prevention ad ( $M_{\text {more-prev }}$ $=4.43)$ and a promotional ad $\left(M_{\text {more-pro }}=\right.$ 4.76) $[F(1,57)=.54, p=.47]$ (See Table 1). As expected, a self-prevention ad led to more recall than a promotional ad, when it was presented with a socially more negative product.
Hence, Hypothesis 1 was supported.

Results also revealed a significant interaction effect of product social acceptance and ad type on ad trust $[F(1,117)=15.46, p<$ .001]. The main effect of ad type was also found $[F(1,117)=26.00, p<.001]$, indicating that a self-prevention ad was perceived as more trustworthy than a promotional ad. Posthoc analyses of one-way ANOVA revealed that when a product was less socially accepted, a self-prevention ad $\left(M_{\text {less-prev }}=4.35\right)$ was more trustworthy than a promotional ad $\left(M_{\text {less-pro }}=2.40\right) \quad[F(1,60)=39.44, p<$ .001]. When the product was more socially accepted in social acceptance, no significant difference in ad trust was found between a self-prevention ad $\left(M_{\text {more-prev }}=3.43\right)$ and $\mathrm{a}$ promotional ad $\left(M_{\text {more-pro }}=3.18\right)[F(1,57)$ $=.71, p=.40]$ (See Table 1). Thus, as expected, negativity of product social acceptance could moderate the effect of a self-prevention ad on ad trust. Therefore, Hypothesis 2 was supported.

Results revealed a significant interaction effect of product social acceptance and ad type on brand attitude $[F(1,117)=4.50$, $p<.05]$. Post-hoc analyses of one-way ANOVA revealed no significant effect of an ad type on brand attitude for both a socially less accepted product and a socially more accepted product. People who were exposed to the self-prevention ad of a less socially accepted product $\left(M_{\text {less-prev }}=3.85\right)$ exhibited more 
positive attitude toward the brand than people who were exposed to the promotional ad $\left(M_{\text {less-pro }}=3.48\right)[F(1,60)=1.43, p=.24]$. When the ad for a socially less accepted product claimed less consumption, brand attitude became more positive compared to that when the ad promoted the product. However, a reverse effect was found for a socially more accepted product. Brand attitude was more positive when the promotional ad was presented $\left(M_{\text {more-pro }}=3.75\right)$ for a socially more accepted product compared to that when the self-prevention ad was presented $\left(M_{\text {more-prev }}=3.26\right)[F(1,57)$ $=3.61, p=.06]$ (See Table 1). Thus, it appears that a self-prevention ad could improve brand image better only when the product category is more negative in social acceptance. Therefore, Hypothesis 3 was partially supported.

\subsection{Short discussions}

In study 1, a cause-related self-prevention ad in which the brand discouraged the purchase of its own products was more effective when the product was more socially concerned. When the product was less socially accepted, a selfprevention ad was attentive and perceived as more trustworthy than a promotional ad. Further, the brand in a self-prevention ad was more positively evaluated than that in a promotional ad. When the advertisers argue a weakness of their products, the ad is viewed as acting against its own interest. Thus, individuals seem to view the self-prevention ad as a means of indicating the advertiser's intention to sacrifice their sales for a social cause.

However, positive effects of the self-prevention ad may not pertain, particularly when individuals hold a strong negative attitude toward the product. Those who are not in favor of the product are motivated to process a self-hurting prevention ad message to be consistent with their pre-established negative attitude, therefore viewing the self-prevention ad as a way of increasing sales for the firm. It is expected that a boomerang effect of the self-prevention ad might occur for those who dislike the product. Therefore, the study 2 was conducted to examine whether individual negative attitude toward a product would negatively influence

〈Table 1〉 Effect of Negative Product Social Acceptance and Ad Type

\begin{tabular}{lcc|cc}
\hline & \multicolumn{2}{c|}{ More socially negative product } & \multicolumn{2}{c}{ Less socially negative product } \\
\cline { 2 - 5 } & $\begin{array}{c}\text { Self-prevention ad } \\
(\mathrm{n}=31)\end{array}$ & $\begin{array}{c}\text { Promotional ad } \\
(\mathrm{n}=31)\end{array}$ & $\begin{array}{c}\text { Self-prevention ad } \\
(\mathrm{n}=30)\end{array}$ & $\begin{array}{c}\text { Promotional ad } \\
(\mathrm{n}=29)\end{array}$ \\
\hline Ad recall* & $5.71(2.36)^{\text {sig }}$ & $4.71(.94)^{\mathrm{sig}}$ & $4.43(1.83)$ & $4.76(1.55)$ \\
Ad trust*** & $4.35(1.27)^{\mathrm{sig}}$ & $2.40(1.18)^{\mathrm{sig}}$ & $3.43(1.33)$ & $3.18(.93)$ \\
Brand attitude* $^{\text {sig }}$ & $3.85(1.04)$ & $3.48(1.40)$ & $3.26(.92)$ & $3.75(1.07)$ \\
\hline
\end{tabular}

Note. Interaction effect ${ }^{*} p<.05,{ }^{* *} p<.01,{ }^{* * *} p<.001$; Posthoc one-way ANOVA test ${ }^{\text {sig }}$ 
the evaluation of the self-prevention ad.

\section{Study 2. Effect of negative consumer attitude on evaluations for a self-prevention ad}

\subsection{Theoretical background}

A self-prevention ad embracing incongruous juxtaposition of information is perceptually distinctive, thus receiving more attention (Arias-Bolzmann et al. 2000). Bless, Bohner, Schwarz, and Strack (1990) found that those who prepositioned a negative attitude toward a product would engage in more effortful and systematic analysis for the target information to generate more negative thoughts, therefore strengthening their prior negative attitude compared to those who had a positive attitude toward the product. Any positive information is not influential enough to relieve the prior negative attitude (Olsen \& Pracejus 2004). While a pro-social message that concurrently devalues a product can produce cognitive conflict, consumers are resistant to change their prior evaluations or attitudes toward the object/person. Thus, they tend to engage in arguments to reject the information in order to be consistent with their negative attitude. This event is more prominent for those who dislike the product.
For example, when a fast food company promotes a healthy diet, those who are critical about fast food may be more disturbed by the structural inconsistency between the self-prevention message and the brand. Consequently, they are motivated to be more attentive. Therefore, the following hypothesis was developed:

$H_{4}$ : For those who have more negative attitude toward a product, they are more likely to recall the self-prevention ad than the promotional ad. However, for those who have less negative attitude toward a product, there is no difference of ad recall between the self-prevention ad and a promotional ad.

Unlike the advertising for a new product, consumers hold their pre-evaluative judgment in order to offend or defend the self-prevention advertising. Preexisting attitude toward the product influences directional interpretation of the self-prevention ad (Jonas et al. 2001; Petty and Cacioppo 1986). Consumers who are favorably predisposed to the product are likely to be more receptive to or less critical about the ad, thus generating more positive cognitive evaluations that are consistent with their prior evaluation of the product. However, when the information threatens the person's attitude, defense motivation arises. Any challenging information that is inconsistent with the prior attitude is more likely to be counter-argued, 
distorted, or rejected in order to avoid or reduce dispositional conflict with the prior evaluations and to preserve prior attitude (Pomerantz et al. 1995). Such defense motivation is more evident among those who are unfavorable toward the product. Bless, Bohner, Schwarz, and Strack (1990) found that a negative attitude could induce a more effortful and systematic analysis for the target information. Those with an opposed stance to the product are likely to engage in generating more counterarguments toward the target in order to be consistent with their negative attitude (Ahluwalia 2000; Jain \& Maheswaran 2000). Therefore, those who like the product view the prevention claim as an honest action to support a social cause. They are likely to interpret the self-prevention ad in a positive direction, generate positive stances. However, when people have a strong negative prior attitude toward a product and encounter a self-prevention ad, their motivation to defend their prepositioned attitude arises. They are likely to diagnose the ad negatively, counter-argue, or infer the intention of the advertiser to a marketing ploy. As compared to those who are favorable toward a product, they are less likely to be receptive to and more critical about the self-prevention ad in order to be consistent with their prior negative attitude. A negative attitude toward a product facilitates greater processing and biased counterargumentations for a self-prevention ad. Based on the literature, the following hypotheses were developed.

$H_{5-1}$ : For those who have more negative attitude toward a product, they are more likely to generate counterarguments on a self-prevention ad than a promotional ad. However, for those who have a less negative attitude toward a product, they are less likely to generate counterarguments on a self-prevention ad than a promotional ad.

$H_{5-2}$ : For those who have more negative attitude toward a product, they are less likely to generate support arguments on a self-prevention ad than a promotional ad. However, for those who have a less negative attitude toward a product, they are more likely to generate support arguments on a self-prevention ad than a promotional ad.

Prior negative attitude is more resistant to attacks from subsequent counter attitudinal advertising messages, thereby resulting in more negative evaluations of the ad and even strengthening the negative attitude. Basil and Herr (2006) found that attitude toward the cause-related activity was less favorable, particularly when consumers hold a negative attitude toward the firm. Attitude was not significantly improved even when the firm worked with charity for philanthropy. Consumers are likely to elaborate on the ulterior motives 
of the advertiser and develop suspicion with regard to the advertiser's ulterior motive to support a social cause (Campbell \& Kirmani 2000). The elaboration and inferences about the possible ulterior motives result in less favorable cause-related activity evaluations of the brand being advertised (Menon \& Kahn 2003). In the presence of negative product information (devaluing the product) in addition to positive information (social cause), consumers who dislike a product generate biased inferences, in which the advertiser feigns being honest and gives less credit on the claim in the ad. If a consumer's prior attitude is positive, the ad claims that argue the negative aspects of a product to a certain degree would be perceived as being trustful and further stimulate more positive evaluations compared to those who argue the positive aspects of a product. Thus, it is expected that for those who are favorable toward a product, the evaluation of a selfprevention ad is more positively biased. However, consumers with a negative attitude can produce more negative responses toward the selfprevention ad, so does the brand. Hence, the following hypothesis was developed:

$H_{6}$ : For those who have more negative attitude toward a product, they are more likely to negatively evaluate the brand in the self-prevention ad than the one in the promotional ad. However, for those who have a less negative attitude toward a product, there is no difference of brand evaluation between the self-prevention ad and a promotional ad.

\subsection{Experiment 2}

\subsubsection{Experimental Manipulation and Procedure}

The experiment for study 2 employed a $2 \mathrm{X}$ 2 between subjects' factorial design: product attitude negativity (more negative vs. less negative) by ad type (promotional vs. selfprevention ad). For the target product, we focused on the tobacco, a less socially accepted product. In this study, the fictitious brand "iMAGINE" was used in order to avoid any confounding effects of preexisting attitude. Target print ads included the main claim (self-prevention vs. promotional), related image, and the brand. In the self-prevention ad condition, a message to prevent smoking was presented with a butterfly image in the center of the ad and the product image at the bottom. In the promotional ad condition, a positive brand concept of iMAGINE was communicated. Two other filler advertisements were presented with the target advertisement located in the middle. In order to assess participant's pre-dispositioned attitude toward the product, participants were asked to rate their attitude toward six product categories, including target product (tobacco) in the middle and four filler products (milk, 
energy bar, chocolate, lottery and burger) prior to the exposure to the experiment stimuli. One hour after the product attitude test, participants were randomly assigned to treatment groups. After viewing the ad booklet, participants were asked to recall the information in the ad and list their thoughts about the ad.

\subsubsection{Results}

A total of 107 undergraduate students (average age of 23 years, including $72 \%$ males) who were recruited on campus participated in this study. Two independent judges excluding the researcher coded the responses of thoughts into three categories: counter arguments, support arguments, and neutral/irrelevant thoughts. The inter-rater reliability was 92 percent. When conflicts surfaced in the coding responses between the two judges, sufficient discussions were made in order to reach a consensus. Considering that the product was socially negative, the attitude of both groups was likely to lean toward negativity, with an average value of less than 4 on the 7-point Likert type scale. Instead of identifying the groups with an absolute bipolar standpoint (positive vs. negative), two groups were split by a median value to more negative attitude group $\left(M_{\text {more }}=\right.$ $\left.1.09, \mathrm{SD}_{\text {more }}=.18, n_{\text {more }}=55\right)$ and less negative attitude group $\left(M_{\text {less }}=3.05, \mathrm{SD}\right.$ less $=1.29$, $n_{\text {less }}=52$ ).

Results of univariate analysis of variance revealed a significant interaction effect of attitude negativity and ad type on ad recall $[F$ $(1,101)=4.30, p<.05]$ (See Table 3). The main effect of ad type was found $[F(1,101)$ $=6.12, p<.05)]$, indicating that the selfprevention ad was more salient and elaborated than the promotional ad. Unexpectedly, no significant difference in recall of the selfprevention ad $\left(M_{\text {more-prev }}=4.85\right)$ versus the promotional ad $\left(M_{\text {more-pro }}=4.71\right)$ was found among those who were more negative against tobacco $[F(1,52)=.09, p=.77]$. People who do not like the product may not seriously consider both types of ad. However, when people had less negative attitude against tobacco, they recalled more information in the selfprevention ad $\left(M_{\text {less-prev }}=5.58\right)$ than the promotional ad $\left(M_{\text {less-pro }}=4.07\right)[F(1,49)=$ 9.47, $p<.01]$. It appeared that those who were less likely to dislike the product paid more attention to the self-prevention ad than the promotional ad. Therefore, Hypothesis 4 was not supported.

Results revealed a significant interaction effect of negative attitude toward the product and ad type on counterarguments $[F(1,103)$ $=4.40, p<.05]$ (See Table 2). Post-hoc analyses of the one-way ANOVA test revealed that among those who were more negative against tobacco, they were likely to make more counterarguments toward the paradoxical ad $\left(M_{\text {more-prev }}=3.11\right)$ than the promotional ad $\left(M_{\text {more-pro }}=2.00\right) \quad[F(1,53)=4.59, p<.05]$. 
However, there was no significant difference in generating counterarguments $\left(M_{\text {less-prev }}=\right.$ 2.04 vs. $M_{\text {less-pro }}=1.81$ ), among those who have less negative attitude toward the product $[F(1,50)=.40, p=.53]$. It appeared that the degree in which people with more negative attitude toward the product generated negative thoughts on a self-prevention ad more than a promotional ad, thereby stimulating a boomerang effect. Those who disliked the product were more consistent with their prior attitude in processing the self-prevention ad cynically, therefore interpreting the self-prevention ad as a way to increase sales. Hence, Hypothesis 5-1 was supported.

A significant interaction effect of negative attitude toward the product and ad type on support argument was found $[F(1,103)=$ 3.99, $p<.05$ ] (See Table 2). The main effect of product attitude was also found $[F(1,103)$ $=6.85, p<.05]$. Post-hoc analyses of oneway ANOVA revealed no significant effect of an ad type on support arguments among people who were more or less negative against smoking. For those who were more negative against tobacco $\left(M_{\text {more-prev }}=.19\right)$ generated less support arguments on the self-prevention ad than the promotional ad $\left(M_{\text {more-pro }}=.25\right)$ $[F(1,53)=.33, p=.57]$. However, the reverse pattern was observed among those who have less negative attitude toward tobacco. They generated more support arguments on the self-prevention ad $\left(M_{\text {less-prev }}=1.08\right)$ than the promotional ad $\left(M_{\text {less-pro }}=.37\right)[F(1,50)$ $=3.47, p=.07]$. It appeared that the self-prevention ad was more effective for those who had a less negative attitude toward tobacco. Therefore, Hypothesis 5-2 was supported.

As expected, the results revealed a significant interaction effect of negative attitude toward the product and ad type on brand evaluation $[F(1,103)=4.50, p<.05]$ (See Table 2). Post-hoc analyses of one-way ANOVA revealed no significant effect of an ad type on brand attitude among people who were more or less negative against smoking. When individuals were more negative against tobacco, a brand in the self-prevention ad was more negatively evaluated than that in the promotional ad $\left(M_{\text {more-prev }}=2.73\right.$ vs. $\left.M_{\text {more-pro }}=3.06\right)[F(1,53)$ $=.97, p=.33]$. However, for those who had less negative attitude toward tobacco, the reverse effect was observed. The brand in the self-prevention ad was more positively evaluated than that in the promotional ad $\left(M_{\text {less-prev }}=\right.$ 4.04 vs. $\left.M_{\text {less-pro }}=3.33\right)[F(1,50)=3.90$, $p=.05]$. In addition, the main effect of attitude negativity toward tobacco was also found $[F$ $(1,103)=10.26, p<.01]$. When people were more negative toward the product, they tended to be persistent with their prior negative attitude in evaluating a brand in any type of advertisements. Therefore, Hypothesis 6 was supported. 
〈Table 2〉 Effect of Negative Attitude toward the Product and Ad Type (Experiment 2)

\begin{tabular}{lcc|cc}
\hline & \multicolumn{2}{c|}{$\begin{array}{c}\text { More negative attitude toward the } \\
\text { product }\end{array}$} & \multicolumn{2}{c}{$\begin{array}{c}\text { Less negative attitude toward the } \\
\text { product }\end{array}$} \\
\cline { 2 - 5 } & $\begin{array}{c}\text { Self-prevention ad } \\
(\mathrm{n}=26)\end{array}$ & $\begin{array}{c}\text { Promotional ad } \\
(\mathrm{n}=28)\end{array}$ & $\begin{array}{c}\text { Self-prevention ad } \\
(\mathrm{n}=24)\end{array}$ & $\begin{array}{c}\text { Promotional ad } \\
(\mathrm{n}=27)\end{array}$ \\
\hline Ad recall* & $4.85(1.71)$ & $4.71(1.58)$ & $5.58(1.74)^{\text {sig }}$ & $4.07(1.75)^{\text {sig }}$ \\
Counter arguments* & $3.11(2.13)$ sig & $2.00(1.66)$ sig & $2.04(1.27)$ & $1.81(1.30)$ \\
Support arguments* & $.19(.40)$ & $.25(.44)$ & $1.08(.87)$ & $.37(.69)$ \\
Brand attitude* & $2.73(1.34)$ & $3.06(1.15)$ & $4.04(1.59)$ & $3.33(.98)$ \\
\hline
\end{tabular}

Note. Interaction effect $* \mathrm{p}<.05,{ }^{* *} \mathrm{p}<.01,{ }^{* * *} \mathrm{p}<.001 ;$ Posthoc one-way ANOVA test ${ }^{\text {sig }}$

\subsubsection{Short discussions}

Study 2 examined whether the positive evaluation of a self-prevention ad for a socially negative product was consistently found among individuals who favored or disliked a product. The results demonstrated evidence of confirmation bias. Attitude was influential for determining the direction of interpreting the information in the ad. Those who were unfavorably disposed to the product were less likely to support the self-prevention ad and more likely to criticize the advertiser's intention behind the selfprevention ad. Consistent with their negative attitude, individuals are therefore motivated to process the self-prevention ad toward a negative direction, thus becoming more involved in processing the ad information. Thus, a negative attitude has a biased point of view in judging the ad information, even when the firm supports a social cause. If the ad contained information contradicting the notion, the product was not positively processed. Rather, it generated more suspicious thoughts. However, those who have a strong negative attitude toward the product did not seem to pay attention differently to the self-prevention ad versus the promotional ad. Because they do not like the product, both types of ads were not seriously considered and memorized. This may lower a sensitive detection of differences in the amount of information in a self-prevention ad. Results of this study were limited to Asian college students.

\section{Discussions and implications}

This research focused on self-prevention ad which a commercial firm might use to discourage its product use in order to be consistent with a social cause. Supporting a certain social cause against a product that the firm promotes can either actually reduce the demand or improve a firm's public brand image.

It was presumed that a way to evaluate the self-prevention ad depends on social acceptance of a product, in which the attributes are 
counteractive against social welfare. The results of this study revealed that product social acceptance could influence the evaluations of the self-prevention ad vs. promotional ad. When a product was less socially accepted, a prevention claim supporting a social cause was more believable, memorable, and positively evaluated than a promotional claim. Therefore, a self-prevention ad was more effective for socially less accepted products. However, supporting a social cause contradictory to the nature of a product does not always stimulate positive responses. Some consumers can react negatively to the self-prevention ad if they have already developed negative attitude toward for the product. This study discovered that those who had a more negative attitude toward a product were more likely to negatively argue the self-prevention ad content. In turn, they negatively evaluated the brand compared to the promotional ad.

Attitude negativity stimulated a boomerang effect for the self-prevention ad. It is evident that the valence of a pre-existing attitude toward a product biased the information processing toward a negative direction. The bias of counter-argumentation clearly occurred among those who disliked the product. Consistent with the defense-motivated evaluative consistency literature (e.g., Bless et al. 1990; Olsen \& Pracejus 2004), the motivation to reject the self-prevention ad was more evident among those who had a negative attitude. When people encounter an inconsistent structure of the information, they are likely to engage in a more negative directional thought processing and produce more cynical thoughts. This also supports the attitude confirmation bias. Those who dislike a product are more likely to devalue the firm's approach of supporting a social cause by contradicting their product in order to confirm their negative attitude. Hence, the self-prevention approach maintains and even strengthens the negative attitude.

Cause-related but self-prevention campaigns need to be carefully designed, in which structural inconsistency exists in the relationship of a message and a message sender, even when the message hurts the message sender. This study adds valuable empirical findings to the existing literature of cause-related prevention advertising; further. It contributes to a new realm of self-prevention advertising along with its effectiveness in marketing research. Past literature in cause-related marketing failed to identify the fit valence in the relationship between a cause and a product. Instead, they only focused on the positive fit in stimulating a positive response to the brand (e.g., Barone et al. 2000; Farrelly et al. 2000). The results in this study provide new findings of fit valence in which, as a product, is more negatively congruent with a social cause.

Our research demonstrated the importance of negative product fit to a social cause in cause-related marketing. Cause-related but 
prevention campaigns against a firm's own product may be more effective for products that are associated with social concerns. As products are more limited in a social context, the communication of product prevention in support of a social cause is beneficial for strengthening the public image of a brand, rather than taking a typical promotional communication approach. The product that is often negatively evaluated by the public or threatens social causes such as carbonated soft drinks, high-calorie candy bars, fast food, beer, and infant formula are more applicable for self-prevention advertising. When the advertiser admits product negativity, consumers view the ad as more believable or honest, therefore inferring that the advertiser intends to communicate true information or sacrifice their own interest in order to be consistent with a social cause. The self-prevention ad gains more attention and increases the motivation to process as the product appears to be more sacrificed. Consequently, the brand featured in a self-prevention ad is better evaluated. More importantly, our research demonstrated the critical role of negative attitude prepositioned prior to the exposure to self-prevention advertising. The findings support previous literature on confirmation bias, in which individuals tend to engage in biased processing and place more effort on processing the conflicted information in order to preserve their prior belief toward the object. This is due to the defense-motivated evaluative consistency.
The motivation to defend the inconsistent information arises when the information challenges the prior attitude. In order to protect their attitude and avoid cognitive conflict, consumers engage in selective information processing and biased interpretation. Confirmation bias is more evident among those who are not favorable toward the product. Those who dislike the product view the self-prevention communication as more skeptical, therefore evaluating the brand with even more negatively. Negative attitude induces more systematic information processing due to defense motivation. Considering that the self-prevention ad is often designed to enhance public brand image, a prevention claim that is contradictory to the product can be carefully selected and polished. The prevention claim countered to the product is more receptive only for consumers who have a positive attitude or less negative attitude toward the product. Thus, it is important for marketers to understand that self-prevention appeals are limited in their effect. They seem to be confined largely to those consumers who are favorable toward the product. The self-hurting approach may be inappropriate for potential customers who currently possess a strong negative attitude toward the product.

Negative attitude did not influence the recalling of the incongruent juxtaposition of information in the ad, although the self-prevention ad was consistently perceived to be more salient than the promotional ad. It seems that inconsistent 
structure of self-prevention advertising may be too sensational, thus attenuating the difference in salience perception for both groups who like or dislike the product. Future research should be performed to examine the effect of product negative fit vs. positive fit to a social cause on brand evaluations. For example, a social cause of "save fuel, save earth" supported by a hybrid automobile manufacturer is perceived to be positively congruent, whereas the same cause claimed by a gas company is perceived to be negatively congruent. Hence, the effectiveness and processing mechanism of a self-prevention ad embedding a negative product fit to a social cause can be investigated as opposed to a typical cause-related ad with a positive product fit. A negative product fit can stimulate intensive processing of incongruent social support, therefore resulting in a positive brand evaluation compared to a positive product fit.

〈Received April 30. 2017〉

〈Accepted August 4. 2017〉

\section{References}

Ahluwalia, R. 2000. 'Examination of psychological processes underlying resistance to persuasion.' Journal of Consumer Research, 27:Sep, 217-232. doi:10.1086/314321

Arias-Bolzmann, L., Chakraborty, G. and Mowen, J. C. 2000. 'Effects of absurdity in advertising: The moderating role of product category attitude and the mediating role of cognitive responses.' Journal of Advertising, 29:1, 35-49. doi:10.1080/00913367.2000.10673602 Barone, M. J., Miyazaki, A. D. and Taylor, K. A. 2000. 'The influence of cause-related marketing on consumer choice: Does one good turn deserve another?' Journal of the Academy of Marketing Science, 28:2, 248-262. doi: 10.1177/0092070300282006

Basil, D. Z. and Herr, P. M. 2006. 'Attitudinal balance and cause-related marketing: An empirical application of balance theory.' Journal of Consumer Psychology, 16:4, 391-403. doi:10.1207/s15327663jcp1604_10

Bless, H., Bohner, G., Schwarz, N. and Strack, F. 1990. 'Mood and persuasion: A cognitive response analysis.' Personality and Social Psychology Bulletin, 16:2, 331-345. doi: 10.1177/0146167290162013

Cacioppo, J. T., Gardner, W. L. and Berntson, G. 1997. 'Beyond bipolar conceptualizations and measures: The case of attitudes and evaluative space.' Personality and Social Psychology Review, 1:Feb, 3-25. doi: 10.1207/s15327957pspr0101_2

Campbell, M. C. and Kirmani, A. 2000. 'Consumers' use of persuasion knowledge: The effects of accessibility and cognitive capacity on perceptions of an influence agent.' Journal of Consumer Research, 27, 69-83. doi:10.1086/314309

Ellen, P. S., Mohr, L. A. and Webb, D. 2000. 
'Charitable programs and the retailer: Do they mix?' Journal of Retailing, 76:3, 393406. doi: 10.1086/208888

Etgar, M. and Goodwin, S. A. 1982. 'One-sided versus two-sided comparative message appeals for new brand introductions.' Journal of Consumer Research, 8: Mar, 460-465. doi:10.1086/208888

Farrelly, M. C., Cheryl G. H., Davis, K. C., Messeri, P., Hersey, J. C. and Haviland, M. L. 2002. "Getting to the truth: Evaluating national tobacco countermarketing campaigns.' American Journal of Public Health, 92:6, 901 - 907. doi: 10.2105/AJPH.92.6.901

Golden, L. L. and Alpert, M. I. 1987. 'Comparative analysis of the relative effectiveness of one- and two-sided communication for contrasting products.' Journal of Advertising; 16:1, 18-68. doi: 10.1080/00913367.1987. 10673056

Jain, S. P. and Maheswaran, D. 2000. 'Motivated reasoning: A depth-of-processing perspective.' Journal of Consumer Research, 26:Mar, 358-371. doi: 10.1086/209568

Jonas, E., Schulz-Hardt, S., Frey, D. and Thelen, N. 2001. 'Confirmation bias in sequential information search after preliminary decision: An expansion of dissonance theoretical research on selective exposure on information.' Journal of Personality and Social Psychology, 80:4, 557-571. doi: 10.1037/0022-3514.80.4.557

Jones, E. E. and Davis, K. E. 1965. 'From acts to dispositions: The attribution process in person perception.' In L. Berkowitz (ed.), Advances in Experimental Social Psychology Vol. II: 219-266. New York: Academic Press.

Kamins, M. A. and Assael, H. 1987. 'Twosided versus one-sided appeals: A cognitive perspective on argumentation, source derogation, and the effect of disconfirming trial and belief change.' Journal of Marketing Research, 24:Feb, 29-39. doi: 10.2307/ 3151751

Kim, S. and Shanahan, J. 2003. 'Stigmatizing smokers: Public sentiment toward cigarette smoking and its relationship to smoking behaviors.' The Journal of Social Psychology, 8:4, 343-367. doi: 10.1080/10810730305723 Lynch, J. G. and Srull, T. K. 1982. "Memory and attentional factors in consumer choice: Concepts and research methods.' Journal of Consumer Research, 9: June, 18-37. doi:10.1086/208893

Maheswaran, D. and Chaiken, S. 1991. 'Promoting systematic processing in low-involvement settings: Effect of incongruent information on processing and judgment.' Journal of Personality and Social Psychology, 61: July, 13-25. doi: 10.1037/0022-3514.61.1.13

Menon, S. and Kahn, B. E. 2003. 'Corporate sponsorships of philanthropic activities: When do they impact perception of sponsor brand?' Journal of Consumer Psychology, 13:3, 316-327. doi: 10.1207/S15327663JCP 1303_12 
Moore, R. S. 2005. 'The sociological impact of attitudes toward smoking: Secondary effects of the demarketing of smoking.' The Journal of Social Psychology, 145:6, 703-718. doi: 10.3200/SOCP.145.6.704-718 OECD. 2013. OECD factbook 2013: Economic, environmental and social statistics. Available at: http://www.oecd-ilibrary.org/sites/ factbook-2013-en/12/02/01/index.html? itemId $=/$ content $/$ chapter/factbook-201398-en

Olsen, G. D. and Pracejus, J. W. 2004. 'Integration of positive and negative affective stimuli.' Journal of Consumer Psychology, 14:4, 374-384. doi:10.1207/s15327663jcp1404_7

Priester, J. R. and Petty, R. 1995. 'Source attributions and persuasion: Perceived honesty as a determinant of message scrutiny.' Personality and Social Psychology Bulletin, 21, 637-654. doi: 10.1177/0146167 295216010

Pomerantz, E. M., Chaiken, S. and Tordesillas, R. S. 1995. 'Attitude strength and resistance processes.' Journal of Personality and Social Psychology, 69:3, 408-419. doi: 10.1037/ 0022-3514.69.3.408
Putrevu, S. and Lord, K. R. 1994. 'Comparative and noncomparative advertising: Attitude affects under cognitive and affective involvement conditions.' Journal of Advertising Research, 23, 77-90. doi: 10.1080/00913367. 1994.10673443

Settle, R. B. and Golden, L. L. 1974. 'Attribution theory and advertiser credibility.' Journal of Marketing Research, 11, 181-185. doi: 10.2307/3150556

Simmons, C. J. and Becker-Olsen, K. L. 2006. 'Achieving marketing objectives through social sponsorships.' Journal of Marketing, 70:4, 154-169. doi:10.1509/jmkg.70.4.154

Smith, R. E. and Hunt, S. D. 1978. 'Attributional processes and effects in promotional situations.' Journal of Consumer Research, 5:Dec, 149-158. doi:10.1086/208725

Stayman, D. M. and Batra, R. 1991.' Encoding and retrieval of ad affect in memory.' Journal of Marketing Research, 28, 232239. doi: $10.2307 / 3172812$

Taylor, S. and Todd, P. 1995. 'Decomposition and crossover effects in the theory of planned behavior: A study of consumer adoption intentions.' International Journal of Research in Marketing, 12, 137-156. doi: 10.1016/0167-8116(94)00019-K 